PDFlib PLOP: PDF Linearization, Optimization, Protection

Page inserted by evaluation version www.pdflib.com - sales@pdflib.com 


\title{
Structure and Catalytic Properties of Protein Tyrosine Phosphatases ${ }^{a}$
}

\author{
JACK E. DIXON \\ Department of Biological Chemistry \\ The University of Michigan Medical School \\ Ann Arbor, Michigan 48109-0606
}

The level of protein tyrosine phosphorylation is controlled within the cell by both tyrosine kinase and phosphatase activities. Our laboratory has focused its energy on the protein tyrosine phosphatases (PTPases). To understand the latter, we and others have cloned a number of PTPases. ${ }^{1,2}$ Now, more than 40 cDNAs are known that encode a wide spectrum of PTPases. The PTPases can be subdivided into two major families. One family of the PTPases resembles receptors: the PTPases have an intracellular tyrosine phosphatase domain(s), a transmembrane domain, and an extracellular domain that may function in cell-cell or ligand-cell interactions. ${ }^{1,2}$ This family has been further classified into five subtypes based largely upon differences in their extracellular domains (FIG. 1). We have a limited understanding of the potential ligands for the receptor-like PTPases. However, the sequence similarity of type II PTPases to cell adhesion molecules (CAM) suggests that these PTPases may exhibit homophilic binding. Expression of $\mathrm{PTP} \mu$ in SF9 insect cells results in cell aggregation, suggesting that the extracellular domains of PTP $\mu$ mediate this self-aggregation, ${ }^{3,4}$ The expression of cytoplasmic domain-deleted constructs indicates that PTPase catalytic activity is not required for adhesion; only the extracellular domain is necessary for cell-cell interactions. The purified extracellular domain conjugated to beads can also mediate bead-bead adhesion. Work from Schlessinger's laboratory also indicates that the closely related molecule PTPK also displays homophilic adhesive properties. ${ }^{5}$ When cells expressing PTP $\mu$ are incubated with cells expressing PTP segregate and adhere in a homophilic fashion. This shows that, although PTP $\mu$ and РTPК are structurally similar, they display a high degree of specificity in their cellcell adhesion.

The second family of PTPases is found exclusively within a cell. ${ }^{1,2,6}$ The distinguishing feature of the intracellular PTPase is the diversity of sequences flanking a single catalytic domain (FIG. 2). One of the functions of these flanking sequences appears to be the targeting of the enzyme to specific intracellular locations. These include (1) membrane-association domains, (2) nuclear-localization domains, (3) Src homology 2 (SH2) domains, and (4) cytoskeletal-association domains. Locating specific PTPases to define subcellular locations will undoubtedly restrict and define their substrate specificity. ${ }^{6}$

\footnotetext{
${ }^{a}$ This work was supported by the National Institutes of Health (NIDDKD 18024) and the Walther Cancer Institute.
} 


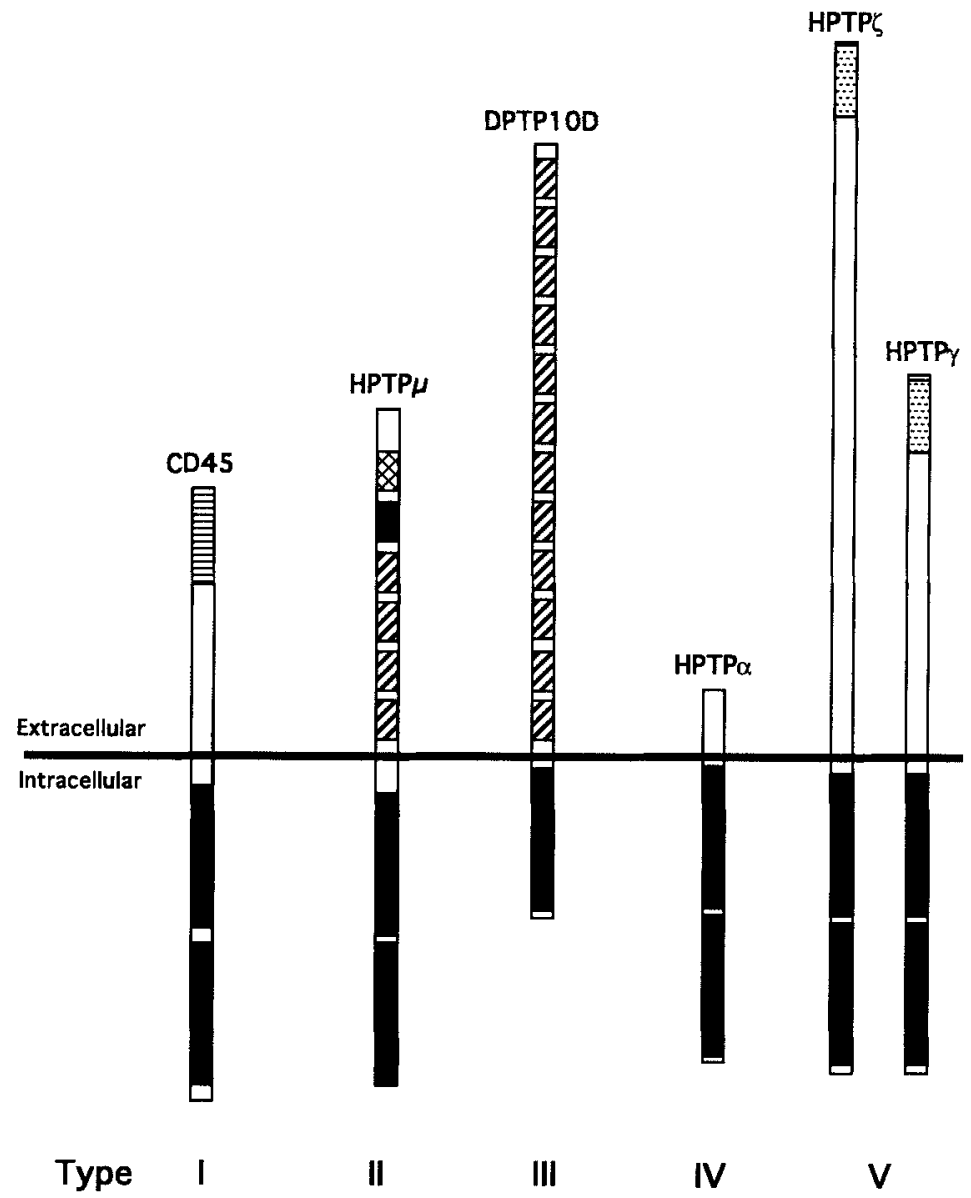

FIGURE 1. Transmembrane receptor-like PTPases. The members of this family of PTPases possess a single transmembrane domain and one or two intracellular PTPase catalytic domains (black bar) (see ref. 16 for details). They can be subdivided into five types on the basis of their extracellular domain structures: I, CD45; II, HPTP $\mu$; III, DPTP10D; IV, HPTP $\alpha$; and V, HPTP $\zeta$ and HPTP $\gamma$. The extracellular domain structures are shown: amino terminus isoforms (horizontal lines) resulting from differential splicing; immunoglobulin-like (vertical lines); fibronectin type III-like (shaded bar); Meprin amino acid motif (MAM) adhesive protein homology-like (diagonal lines); and carbonic anhydrase-like (stippled). (Mauro \& Dixon. ${ }^{6}$ With permission from Elsevier Trends Journals.)

We discovered that certain pathogenic bacteria also have a protein that has protein tyrosine phosphatase activity. ${ }^{7}$ This is unusual because bacteria are not known to contain proteins that are phosphorylated on tyrosine. The bacteria that have the tyrosine phosphatase activity are from the genus Yersinia. This bacterium was responsible for the plague or the Black Death that reduced the population of Europe on several 


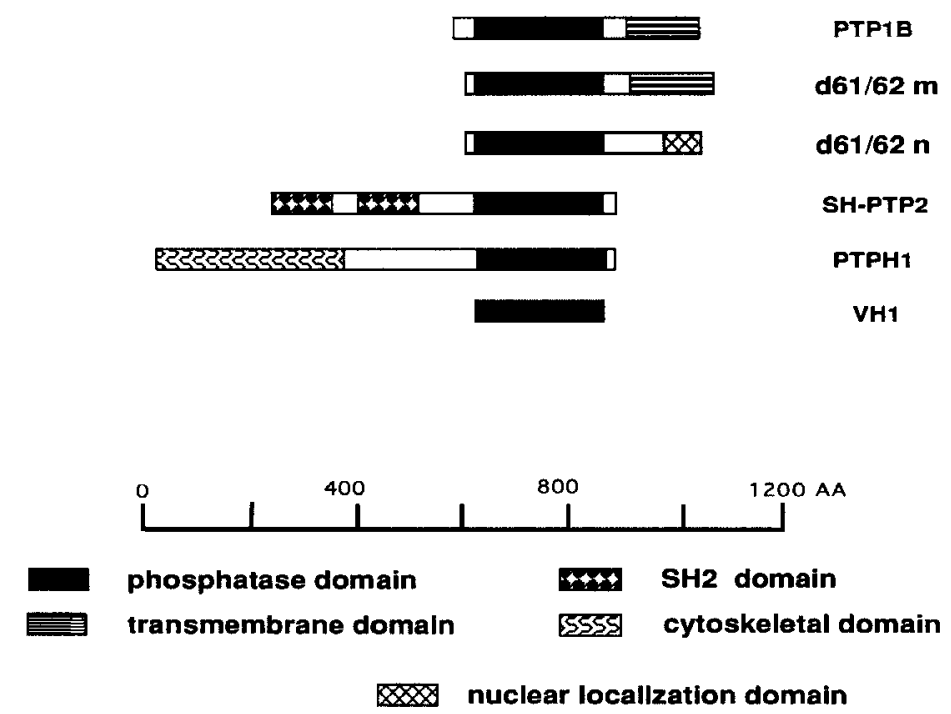

FIGURE 2. Structural features of representative intracellular PTPase. Each PTPase possesses one conserved catalytic domain. The PTPase pictured with their corresponding noncatalytic sequences include (a) membrane-association domains in PTP1B; (b) an Src homology 2 (SH2) domain in SH-PTP2; and (c) cytoskeleton-association domains in PTPH1. (Mauro \& Dixon. ${ }^{6}$ With permission from Elsevier Trends Journals.)

occasions by more than 25 million people. As you are well aware, the plague has recently broke out again in India. This simply points out that such diseases, although treatable by antibodies, have not been eliminated as human pathogens. We have shown that the Yersinia PTPase is a virulent gene in bacterium and that it functions to dephosphorylate tyrosine residues necessary for regulating mechanisms within the mammalian host. ${ }^{8}$

We also observed that the vaccinia virus and other members of the pox virus family (including small pox) have encoded within their genomes a phosphatase. The activity of the vaccinia phosphatase is not restricted to the dephosphorylation of tyrosine; it will also dephosphorylate serine- and threonine-containing substrates. ${ }^{9}$ The vaccinia phosphatase has an amino acid sequence identity to the yeast cell cycle gene product, cdc 25 , and a group of related mammalian dual-specific phosphatases. TABLE 1 lists representatives of the various dual-specific phosphatases that have been described to date. ${ }^{10}$

All PTPases possess at least one 230 amino acid catalytic domain containing a highly conserved active-site region with the consensus motif [I/N]HCXAGXXR[S/ T]G (where $X$ is any amino acid). This region is the signature sequence of most PTPases. ${ }^{11,12}$ Site-directed mutagenesis and trapping experiments have shown that the cysteinyl residue within this motif is essential for phosphatase activity. The enzyme appears to form a thiol-phosphate intermediate during catalytic turnover. ${ }^{13}$ Interestingly, this catalytic domain of the PTPases bears no resemblance to that of the serine-threonine phosphatases or of the alkaline or acid phosphatases. Recently, 
TABLE 1. The Dual-specific PTPases

\begin{tabular}{|c|c|c|c|}
\hline $\begin{array}{l}\text { Dual-specific } \\
\text { PTPases }\end{array}$ & $\begin{array}{l}\text { Substrate } \\
\text { Motif }\end{array}$ & Induction & Function \\
\hline $\begin{array}{l}\text { HVH1, CL100, } \\
\text { SCH134, MKP-1 }\end{array}$ & $-(p T) E(p Y)-$ & $\begin{array}{l}\text { Serum, growth fac- } \\
\text { tors, phorbol esters }\end{array}$ & $\begin{array}{l}\text { Deactivation of } \mathrm{ERK}^{a}, \mathrm{MAP}^{b} \\
\text { kinase }\end{array}$ \\
\hline PAC1 & $-(p T) E(p Y)-$ & T-cell activation & $\begin{array}{l}\text { Deactivation of ERK-MAP } \\
\text { kinase }\end{array}$ \\
\hline $\mathrm{Cdc} 25$ & $-(\mathrm{pT})(\mathrm{pY})-$ & Cell cycle-dependent & $\begin{array}{l}\text { Activation of Cdc2; entry } \\
\text { into mitosis }\end{array}$ \\
\hline KAP, Cdi1 & $-(p T)(p Y)-$ & Cell cycle-dependent & $\begin{array}{l}\text { Cell-cycle regulation; associ- } \\
\text { ates with } \mathrm{CDK} 2 \text {, cdc2 }\end{array}$ \\
\hline YVH1 & - & Nitrogen starvation & Growth control \\
\hline MSG5 & $-(p T) E(p Y)-$ & Mating pheromone & $\begin{array}{l}\text { Inactivation of FUSS: adapta- } \\
\text { tion to pheromone re- } \\
\text { sponse in yeast }\end{array}$ \\
\hline
\end{tabular}

${ }^{a}$ Extracellular signal-regulated kinase.

${ }^{b}$ Mitogen-activated protein.

the structures of two PTPases have been solved. ${ }^{14,15}$ Their structures are quite similar and support the idea that the PTPase most likely employs a common catalytic mechanism. Details of the structure and the catalytic mechanism will be discussed.

\section{REFERENCES}

1. Walton, K. M. \& J. E. Dixon. 1993. Protein tyrosine phosphatases. Annu. Rev. Biochem. 62: $101-20$.

2. Fischer, E. H., H. Charbonneau \& N. K. Tonks. 1991. Protein tyrosine phosphatases: a diverse family of intracellular and transmembrane enzymes. Science $253(5018)$ : 401-6.

3. Brady-Kalnay, S. M., A. J. Fuint \& N. K. Tonks. 1993. Homophilic binding of PTP $\mu$, a receptor-type protein tyrosine phosphatase, can mediate cell-cell aggregation. J. Cell Biol. 122: $961-972$.

4. Gebink, M. F. B. G., G. C. M. Zondag, R. W. Wubbolts, R. L. Beijersbergen, I. VAN EtTEN \& W. H. MoolenaAR. 1993. Cell-cell adhesion mediated by a receptorlike protein tyrosine phosphatase. J. Biol. Chem. 268: 16101-16104.

5. SaP, J., Y. P. Jiang, D. Friedlander, M. Grumet \& J. Schlessinger. 1994. Receptor tyrosine phosphatase R-PTP-kappa mediates homophilic binding. Mol. Cell. Biol. 14(1): $1-9$.

6. Mauro, L. J. \& J. E. Dixon. 1994. “Zip codes” direct intracellular protein tyrosine phosphatases to the correct cellular "address." TIBS 19(4): 151-155.

7. GuAN, K. \& J. E. DixoN. 1990. Protein tyrosine phosphatase activity of an essential virulence determinant in Yersinia. Science 249: 553-556.

8. Bliska, J. B., K. Guan, J. E. Dixon \& S. Falkow. 1991. Tyrosine phosphate hydrolysis of host proteins by an essential Yersinia virulence determinant. Proc. Natl. Acad. Sci. USA 88: $1187-1191$. 
9. Guan, K., S. S. Broyles \& J. E. Dixon. 1991. A Tyr/Ser protein phosphatase encoded by Vaccinia virus. Nature 350: 359-362.

10. Tonks, N. K., A. J. Flint, M. F. B. G. Gebbink, H. Sun \& Q. Yang. 1993. Signal transduction and protein tyrosine dephosphorylation. Adv Second Messenger Phosphoprotein Res. 28: 203-210.

11. ZHANG, Z.-Y. \& J. E. Dixon. 1994. Protein tyrosine phosphatases: Mechanism of catalysis and substrate specificity. Adv. Enzymol. 68: 1-36.

12. ZhANG, Z.-Y. \& J. E. Dixon. 1993. Active site labeling of the Yersinia protein tyrosine phosphatase: The determination of the pKa of the active site cysteine and the function of the conserved histidine 402. Biochemistry 32(36): 9340-9345.

13. GuAN, K.-L. AND J. E. DixON. 1991. Evidence for protein tyrosine phosphatase catalysis proceeding via a cysteine-phosphate intermediate. J. Biol. Chem. 266(26): 1702617030.

14. Barford, D., A. J. Flint \& N. K. Tonks. 1994. Crystal structure of human protein tyrosine phosphatase 1B. Science 263(5152): 1397-1404.

15. Stuckey, J., H. Schubert, E. Fauman, Z.-Y. Zhang, J. E. Dixon \& M. Saper. 1994. Crystal structure of Yersinia protein tyrosine phosphatase at $2.5 \AA$ and the complex with tungstate. Nature 370: 571-575.

16. Mourey, R. J. \& J. E. Dixon. 1994. Protein tyrosine phosphatases: characterization of extracellular and intracellular domains. Curr. Opinion Genet. Dev. 4: 31-39. 